\title{
Home Range Characteristics of the Released Female Milu (Père David's Deer, Elaphurus davidianus) Population during Different Periods and Effects of Water Submersion in Dongting Lake, China
}

\author{
Shuangye Wang ${ }^{1,2}$, Yunlin Zhao ${ }^{1,2}$, Zhenggang $\mathrm{Xu}^{2,3, *}$, Junzhi Chen ${ }^{3}$, Guiyan Yang \\ Song Wang ${ }^{2}$ and Kangkang Jiang ${ }^{2}$ \\ ${ }^{1}$ College of Resources \& Environment, Hunan Agricultural University, Changsha \\ 410128, China \\ ${ }^{2}$ Engineering Research Center for Internet of Animals, Central South University of \\ Forestry and Technology, Changsha 410000, China \\ ${ }^{3}$ Key Laboratory of National Forestry and Grassland Administration on Management \\ of Western Forest Bio-Disaster, College of Forestry,, Northwest A \& F University, \\ Yangling, 712100, China
}

\section{A B S T R A C T}

To understand home range characteristics and distribution of the released female milu (Père David's deer, Elaphurus davidianus) population at Dongting Lake, China, we estimated home range size using the $95 \%$ minimum convex polygon method. A maximum flooded time index was calculated and the overlay analysis with seasonal home range data was employed. The results showed: (1) in seasons, the home range size of winter was the largest while it was the smallest in summer. It was also found that home range of dry and wet periods in 2017 was larger than in 2016 for the same period; (2) The milu population lived together in the released area. They even moved to outside of Dongting Lake in summer and moved back in autumn with the water level change. The milu population separated into several groups during the movement process; (3) By combining home range and the maximum flooded time index map, the milu population habitat covered various types of land use and active area when water source was included. While managing the two types of land use these should be connected by vegetation and should not be too far apart. In general, the home range distribution and size changed with the changing periods i.e. dry period and wet period. Available space, food resources, and shelter were influenced by water level variation in Dongting Lake, and water level may be the main factor affecting the distribution and home range size of milu population, indirectly utilizing the habitat.

\begin{tabular}{l} 
Article Information \\
Received 20 December 2019 \\
Revised 22 May 2020 \\
Accepted 27 February 2021 \\
Available online 19 May 2021 \\
(early access) \\
Published 15 February 2022 \\
Authors' Contribution \\
YZ and ZX designed the project. \\
Shuangye Wang, SW and KJ traced \\
the species population in the wild, \\
recorded the location and prepared \\
necessary image data. SW, JC and GY \\
wrote the manuscript. \\
Key words \\
\hline Milu, Père David's deer, Satellite \\
tracking, Home range, Maximum \\
flooded time index, Dongting Lake.
\end{tabular}

\section{INTRODUCTION}

$\mathrm{H}$ ome range (HR) is defined as the area utilized during an animal's normal daily activities, such as food gathering, mating, and caring for the young (Burt, 1943). Shape, size, structure of the HR and the relationship between HR and the environment are key components of animal ecology (Kaczensky et al., 2010). Mammals appear to have larger HR sizes when they live in less productive habitats or where food resources are distributed unevenly (Rautio et al., 2013). Patterns of spatial utilization and population distribution reveal significant information regarding animal biology and behavior (Sarkar et al., 2016). Furthermore, an understanding

\footnotetext{
Corresponding author: xuzhenggang@nwafu.edu.cn 0030-9923/2022/0003-1133 \$ 9.00/0

Copyright 2022 Zoological Society of Pakistan
}

of how animals use their HR is important for managing wildlife (Kernohan, 2001; Willems and Hill, 2009).

Milu (Elaphurus davidianus, also called the Père David's deer) is endemic to China (Yang et al., 2016). Milu is a typical species that was reintroduced from Europe to China in the 1980 s, nearly a century after its extirpation due to natural factors and human disturbances (Ding, 2018). There are three milu breeding and protective organizations, including Beijing Milu Park, Jiangsu Dafeng Milu National Nature Reserve, and Hubei Shishou Milu National Nature Reserve. Milu prefer the habitat where food is abundant, near the water and far away from human activity (He et al., 2007). Liang and Li (1991) have investigated plants which milu consume, and found that plants with low amounts of fibrous material were usually chosen by them. Milu populations now have become more adapted to human activities than when they lived in the wild prior to their extirpation (Jiang et al., 2001). During 
breeding season, male individuals compete for mating opportunities, all male milu can be classified into three ranks as King, Challenger and Bachelor (Liu, 2014). With the increase in captive milu population, the restoration of wild population, there is increased possibility of establishing wild populations (Zhang et al., 2011). A previous study on the mitochondrial DNA control regions in milu showed low genetic diversity (Meng et al., 2014). While making efforts to further restore the wild milu population, captive bred, milu have been released in the wild many a times in recent years (Li et al., 2007).

Before extinction in the wild, milu was widely distributed in Dongting Lake. Due to flood damage in 1998, the milu in Hubei Shishou Milu National Nature Reserve migrated to Dongting Lake wetland and formed natural wild populations (Song et al., 2015). In order to monitor the recovery process of milu populations, 16 milu individuals from Jiangsu Dafeng Milu National Nature Reserve were selected for release in Dongting Lake wetland, and ten female individuals were fitted with satellite tracking equipment (Wang et al., 2019). The aim of this paper is to supervise the home range (HR) variety of released milu population and explore the relationship between HR and water level changes.

\section{MATERIALS AND METHODS}

\section{Study site}

The Dongting Lake wetland $\left(28^{\circ} 30^{\prime}-30^{\circ} 20^{\prime} \mathrm{N}\right.$, $\left.111^{\circ} 40^{\prime}-113^{\circ} 10^{\prime} \mathrm{E}\right)$ is located in the middle reaches of the Yangtze River region, China, where the elevation at the soil surface ranges from $28 \mathrm{~m}$ to $35 \mathrm{~m}$ above sea level (Li et al., 2013, 2019; Liang et al., 2015; Wang et al., 2017). The rainfall of Dongting Lake shows seasonal variation. The mean average rainfall has been $1429 \mathrm{~mm}$ in recent years of which approximately $70 \%$ occurred in wet periods, which lasted from May to October (Chen et al., 2016; Zhang et al., 2016). During the wet season, the lake expanded to a large water surface area, attaining an average area of $2050.5 \mathrm{~km}^{2}$ during the period $2003 \sim 2010$. The lake bottom during the dry season (from November to April of the next year), attained an average area of water surface $1002.7 \mathrm{~km}^{2}$ during the same period (Tian et al., 2012; Lai et al., 2013). Six habitat types identified in the lake include open water, mudflats, Carex marshes, reed marshes, forests, and other areas (Guan et al., 2016). The Dongting Lake recognized as the key region for numerous overwintering migratory water birds (Cao et al., 2008). Large sarcophagous animals such as wolves do not occur, however some domesticated ungulates occasionally appear. A large number of human beings live in the lake that affects the activity of milu (Cao et al., 2010). Considering the climate, resources and environmental conditions, the Dongting Lake wetland is the ideal habitat for milu populations (Yang et al., 2002, 2007).

\section{Period partition and home range (HR) size estimation}

The re-introduction project was guided by Chinese Forestry and Grassland Administration and implemented by Hunan Provincial Government and Hunan Wild Animal Rescue and Breeding Center. HQAN40L collars were used whose data acquisition frequency was set to once an hour all the days (http://www.hqxs.net/Home/Index). The location data of 10 female milu were collected from March 4, 2016 to July 29, 2017, lasting more than one year with the total amount of 48,174 . During the whole experimental process, the animal welfare was concerned. The Animal Ethics Committee, Central South University of Forestry and Technology provided full approval for this study. To explore more details about the HR characteristics of the female milu population, we divided the location data into different periods based on seasonal change and water level characteristics in Dongting Lake in relation to that of the female milu.

The period partition was defined and divided as follows: 1) based on seasonal transformation, the period was divided into spring (March to May), summer (June to August), autumn (September to November) and winter (December to February the following year); 2) considering water levels, the wet period (May to October) and dry period (November to April the following year) were separated. Only when there were data for each month of above period, the period was considered. For example, if location data for one individual existed for March, April and May, then the spring period was chosen. If there were data just for one or two month, the period was not used.

HR size was estimated using "Home range Tools (HRT)" in ArcGIS 10.2. According to previous studies, we chose the minimum convex polygon (MCP) (Reinecke et al., 2014; Flanagan et al., 2016; Plotz et al., 2016) method. All location points of the ten individuals were combined and the HR was calculated by $95 \% \mathrm{MCP}$.

\section{Water surface variation monitoring}

The water surface area of Dongting Lake fluctuates regularly, which greatly affects the habitat. Terra/MODIS data were selected to monitor variations of the water surface area of Dongting Lake. Based on the visible light and near-infrared band remote sensing imagery, the water body area was extracted from other land cover types. MOD09Q1 was MODIS image which update every 8-day, and all MOD09Q1 data during 2016 and 2017 were downloaded from LAADS DAAC (Huang et al., 2012) (http://ladsweb.modaps.eosdis.nasa.gov/). Images 
obscured due to cloud cover were omitted from the study, yielding 34 images from 2016 and 25 images from 2017. These 59 images were re-projected to the commonly used projection of the Universal Transverse Mercator (WGS84) using the nearest neighbour re-sampling method with the MODIS Reprojection Tool. To eliminate the influence of water plants, sediment, soil moisture content and clouds, the water body extraction steps in the study, including the three rules listed below, relied on band1, band2, and NDVI of the MODIS data: (1) If NDVI $\leq 0.1$, the pixel could be identified as a water body. The NDVI value is influenced by climate and landscapes, but 0 could not be used as a threshold value to extract water because there are many water plants in Dongting Lake from April to September. Referring to previous study regarding threshold ranges from -0.1 to 0.3 (Tan, 2002), we selected 0.1 as the threshold based on our visual opinion by comparing with original image. (2) If the DNband $2<1400$, the pixel could be identified as a water body. The band2 of MOD09Q1 is a near-infrared band in which the characteristics of plants and soil are opposite to those of water bodies. When the threshold is between 1,000 and 1,400 (Huang et al., 2012), water bodies can be distinguished from other landscape, such as build-up and bare soil. As in rule (1), 1400 was selected as the threshold with the help of visual assessment. (3) To eliminate the influence of clouds, based on rules
(1) and rule (2), if DNband1 $>2,000$ and DNband2 $>2,000$, then the pixel could be identified as non-water body.

The value of water bodies and non-water bodies was defined as 1 and 0 , respectively. Then the images were combined based on the period partition and estimated maximum flooded time index (MSTI) of each period using the band calculator in ArcGIS 10.2 software. The MSTI was divided into seven degrees (A, B, C, D, E, F, G) (Huang et al., 2019). The MSTI area and percent of each degree were calculated using ArcGIS 10.2. First, the MSTI map was reclassified based on the value range of each degree, then counted the number of raster. Finally, the acreage and percent was calculated.

\section{Overlay analysis of HR and water variation}

Considering the seasonality of water surface variation of Dongting Lake, the MSTI map was estimated for 2016 and 2017, respectively. To explore the utilization of MSTI by the female milu population of Dongting Lake, the HR of seasons were overlayed with the MSTI map. Moreover, the MSTI of each period was calculated, and they were clipped by the relevant HR. The utilization proportion of seven degrees in each period was calculated according to the count of raster. The workflow diagram of the present study is shown in Figure 1.

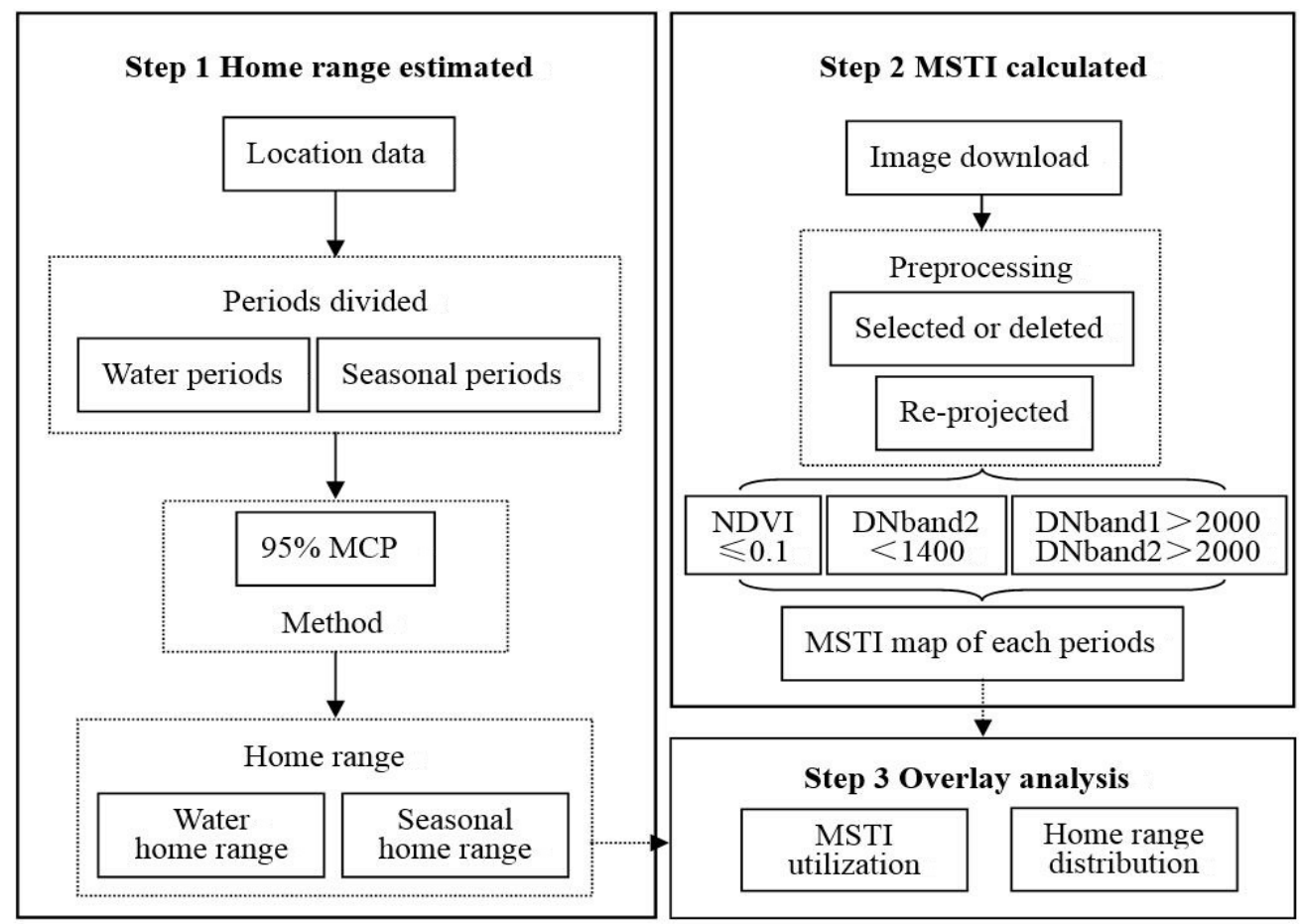

Fig. 1. Water extraction and seasonal home range overlay analysis procedures. "MCP" represents minimum convex polygon method, "MSTI" represents maximum flooded time index. 

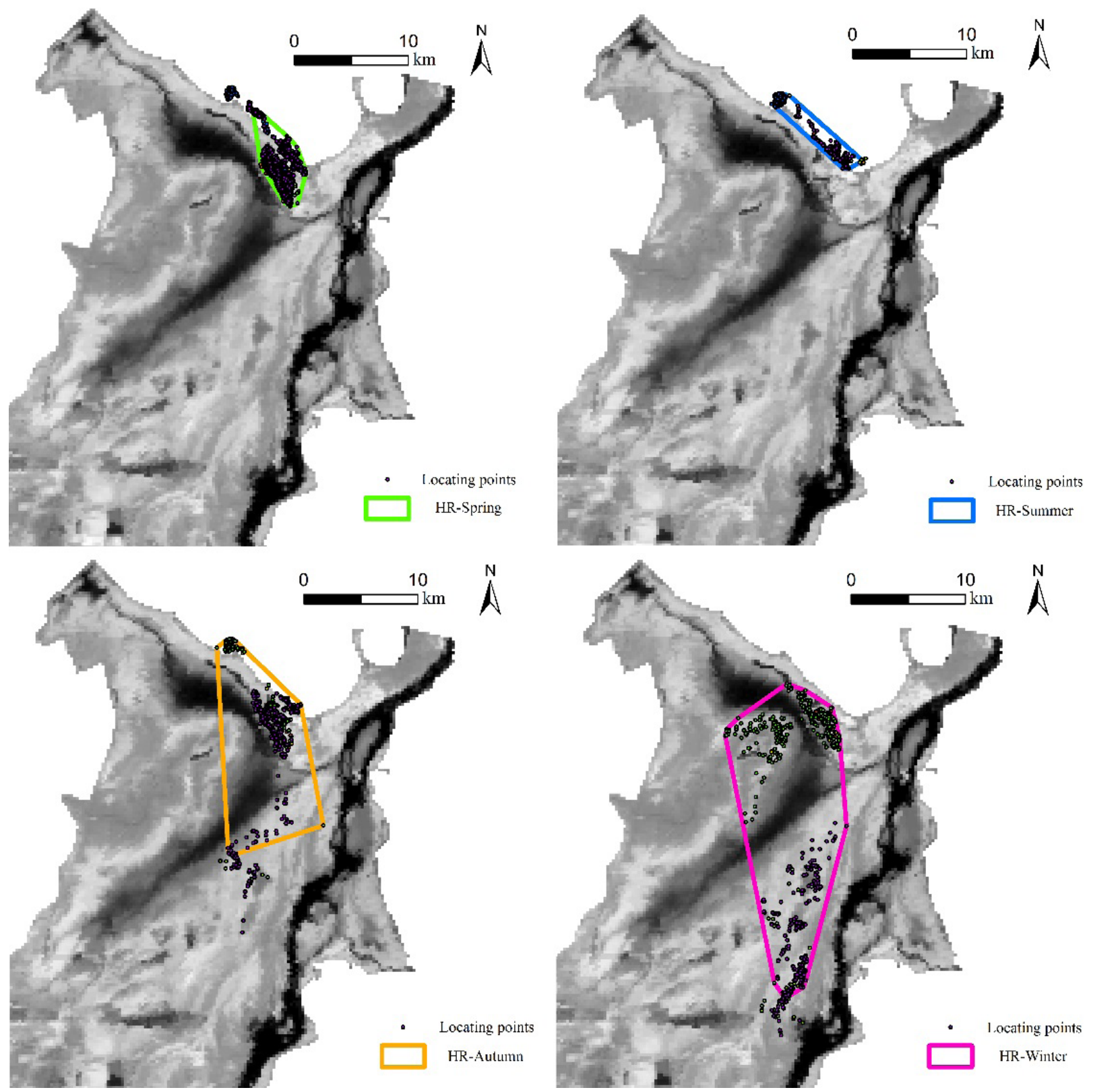

Fig. 2. The home range distribution of milu population in different seasons (March, 2016 to February, 2017).

\section{RESULTS}

At times due to the influence of satellite signals, sometimes positioning information could not be obtained. Some tracking devices stopped working at a later stage. The study collected 48,174 location data on 10 female individuals in total; the mean number for each animal was nearly 5000. The positioning data concentrated in 2016 and only 5 milu were tracked in 2017, including milu 02 , milu04, milu05, milu06, milu10 (Table I).

\section{$H R$ variations during different seasons}

All the location data of 10 individuals were collected during different seasons with different colors (Fig. 2). The HR size in summer was the smallest in seasons (14.34 $\mathrm{km}^{2}$ ), while the maximum HR of winter was $187.39 \mathrm{~km}^{2}$ (Table II). When the area of the HR was small, such as spring and autumn, the activity area of the milu population was mainly concentrated along the shore of Dongting Lake, and even migrated to areas outside Dongting Lake. With the expansion of the HR, the milu population expanded to 
the core area of Dongting Lake.

\section{HR variation during different water periods}

Two representative periods were identified, based on water level. The milu inhabited the Dongting Lake area and outside of the lake during both the periods (Fig. 3). Many location points conformed to the period partition, dry period and wet period both formed in 2016 and 2017. In 2016 , the HR size, both in dry and wet periods was less than $50 \mathrm{~km}^{2}$. HR in dry season was less than that in wet period. However, the HR of dry period was nearly 300 $\mathrm{km}^{2}$ in 2017 , larger than in wet period in which the HR was $69.48 \mathrm{~km}^{2}$ (Table II). According to the points of each individual, the milu population migrated and constituted different groups from 2016 to 2017.

\section{Maximum submersion time index of Dongting Lake}

Because of the seasonal change in water level, the MSTI was higher in the inner lake and mainstream, and decreased gradually towards the lake edges. Compared with 2016, the MSTI increased near the inner lake and mainstream in 2017. The MSTI changed inconspicuously at the two poles, and bottomland with low MSTI was similar between 2016 and 2017 (Fig. 4).

\section{Relationship of HR and water variation}

The distribution of milu population changed over time (Fig. 5). The milu population lived in the release area together in spring, then they moved outside the lake in summer until water level receded. Some milu individuals

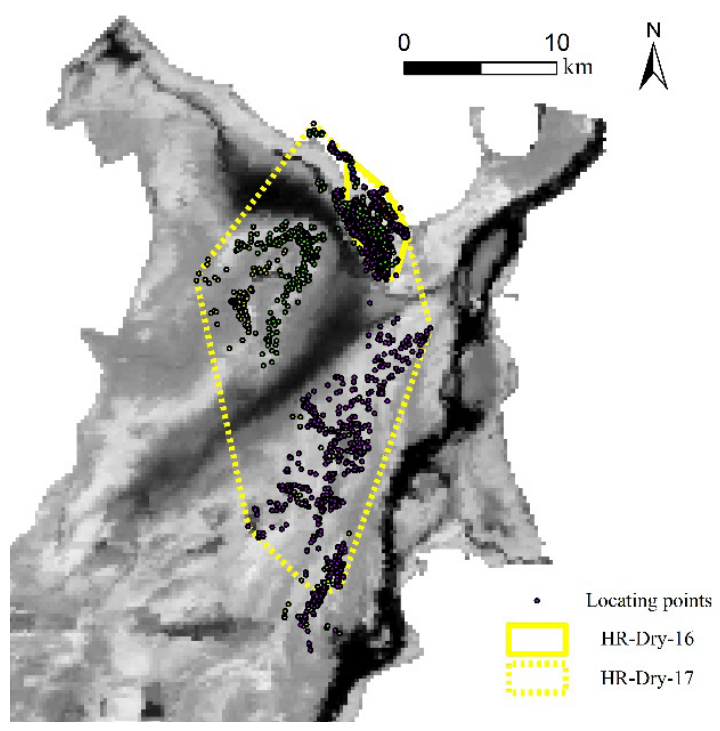

also travelled through the inner lake to find the suitable habitat.

Table I.- Location data of milu individuals.

\begin{tabular}{lclcc}
\hline Milu ID & $\begin{array}{c}\text { Tracker } \\
\text { ID }\end{array}$ & Sex & $\begin{array}{c}\text { Location } \\
\text { data No. }\end{array}$ & Time span \\
\hline Milu01 & HNRC001 & Female & 4481 & $2016 / 3 / 4-2016 / 8 / 14$ \\
Milu02 & HNRC002 & Female & 5653 & $2016 / 3 / 4-2017 / 7 / 29$ \\
Milu03 & HNRC003 & Female & 4516 & $2016 / 3 / 4-2016 / 9 / 15$ \\
Milu04 & HNRC004 & Female & 6142 & $2016 / 3 / 4-2017 / 7 / 29$ \\
Milu05 & HNRC005 & Female & 5124 & $2016 / 3 / 4-2017 / 3 / 15$ \\
Milu06 & HNRC008 & Female & 4688 & $2016 / 3 / 4-2017 / 3 / 17$ \\
Milu07 & HNRC009 & Female & 2976 & $2016 / 3 / 4-2016 / 5 / 26$ \\
Milu08 & HNRC014 & Female & 3633 & $2016 / 3 / 4-2016 / 7 / 20$ \\
Milu09 & HNRC015 & Female & 4189 & $2016 / 3 / 4-2016 / 8 / 30$ \\
Milu10 & HNRC017 & Female & 6772 & $2016 / 3 / 4-2017 / 5 / 5$ \\
\hline
\end{tabular}

Table II.- Home range area in different periods using 95\% MCP.

\begin{tabular}{llcc}
\hline & Period & Time span & Area $\left(\mathbf{k m}^{2}\right)$ \\
\hline Seasons & Spring & $2016 / 3 / 1-2016 / 5 / 31$ & 20.83 \\
& Summer & $2016 / 6 / 1-2016 / 8 / 31$ & 14.34 \\
& Autumn & $2016 / 9 / 1-2016 / 11 / 30$ & 117.84 \\
& Winter & $2016 / 12 / 1-2017 / 2 / 28$ & 187.39 \\
Water period & Dry-16 & $2016 / 1 / 1-2016 / 4 / 30$ & 18.72 \\
& Dry-17 & $2016 / 11 / 1-2017 / 4 / 30$ & 295.37 \\
& Wet-16 & $2016 / 5 / 1-2016 / 10 / 31$ & 30.89 \\
& Wet-17 & $2017 / 5 / 1-2017 / 10 / 31$ & 69.48 \\
\hline
\end{tabular}

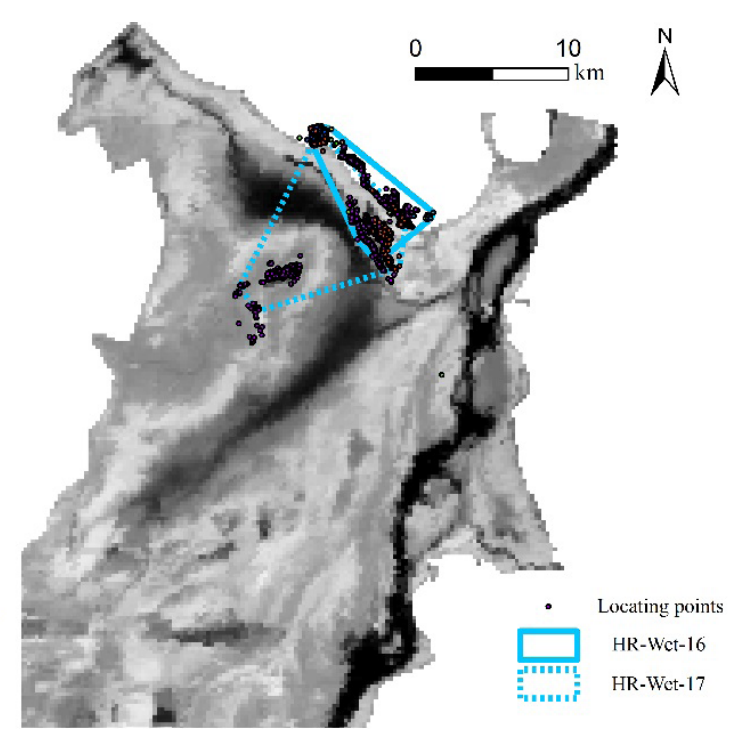

Fig. 3. The home range distribution of milu population in different water periods. The "HR-period-16" represents period in 2016, "HR-period-17" represents period in 2017. 


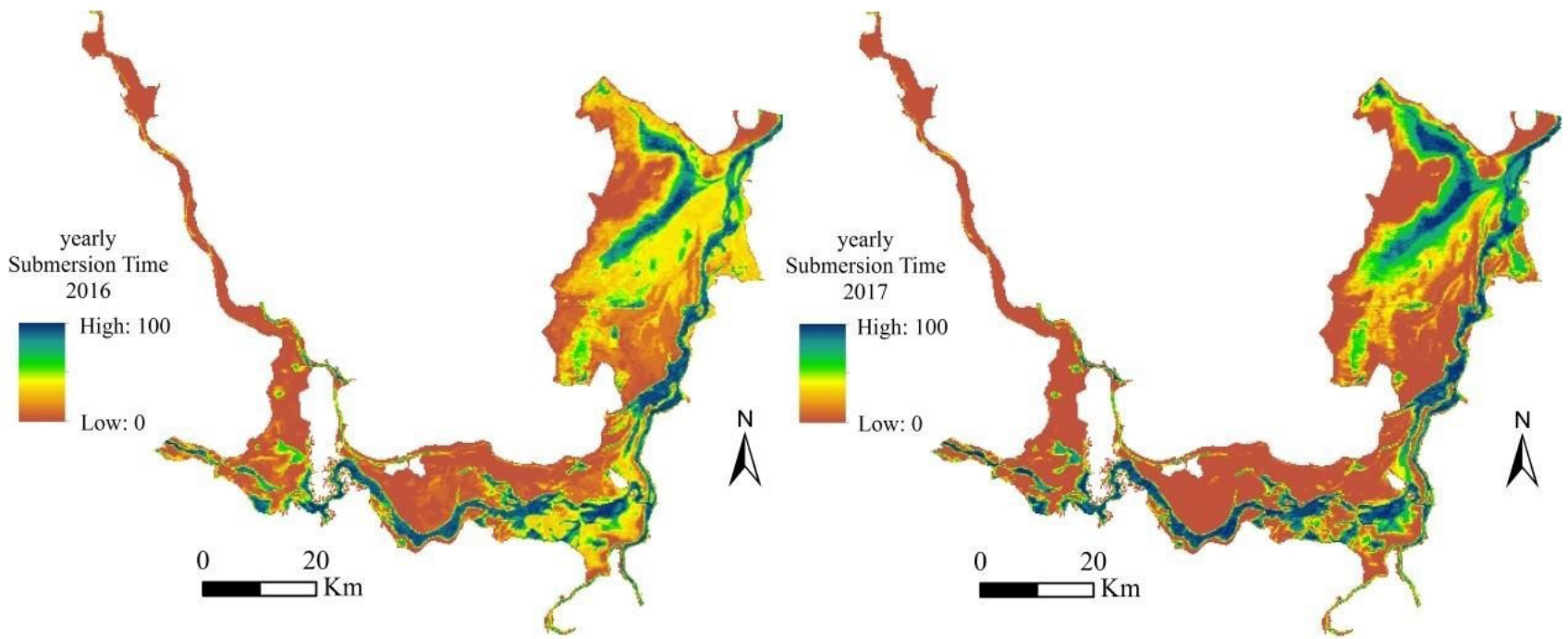

Fig. 4. Average yearly max-submersion time index of Dongting Lake in 2016 and 2017.

Table III.- The MSTI trend in different seasons and water periods.

\begin{tabular}{llcccccccc}
\hline Levels & MSTI & \multicolumn{7}{c}{ Area $\left(\mathbf{k m}^{2}\right)$ and percent } \\
\cline { 3 - 8 } & & Spring & Summer & Autumn & Winter & Dry-16 & Dry-17 & Wet-16 & Wet-17 \\
\hline A & 0 & 1271.44 & 638.06 & 1760.00 & 1977.31 & 1361.00 & 1608.63 & 614.63 & 1234.94 \\
& & $(46.43 \%)$ & $(23.30 \%)$ & $(64.27 \%)$ & $(72.20 \%)$ & $(49.70 \%)$ & $(58.74 \%)$ & $(22.44 \%)$ & $(45.10 \%)$ \\
B & $(0 \% \sim 20 \%)$ & 0 & 254.81 & 182.94 & 113.31 & 308.63 & 259.19 & 416.88 & 173.50 \\
& & $(0 \%)$ & $(9.30 \%)$ & $(6.68 \%)$ & $(4.14 \%)$ & $(11.27 \%)$ & $(9.46 \%)$ & $(15.22 \%)$ & $(6.34 \%)$ \\
C & {$[20 \% \sim 40 \%)$} & 164.19 & 207.56 & 123.81 & 85.00 & 481.50 & 238.00 & 390.44 & 211.56 \\
& & $(6.00 \%)$ & $(7.58 \%)$ & $(4.52 \%)$ & $(3.10 \%)$ & $(17.58 \%)$ & $(8.69 \%)$ & $(14.26 \%)$ & $(7.73 \%)$ \\
D & {$[40 \% \sim 60 \%)$} & 181.88 & 413.75 & 187.50 & 152.69 & 139.44 & 138.13 & 469.13 & 174.63 \\
& & $(6.64 \%)$ & $(15.11 \%)$ & $(6.85 \%)$ & $(5.58 \%)$ & $(5.09 \%)$ & $(5.04 \%)$ & $(17.13 \%)$ & $(6.38 \%)$ \\
E & {$[60 \% \sim 80 \%)$} & 366.50 & 276.38 & 87.75 & 80.69 & 193.44 & 116.13 & 451.31 & 261.69 \\
& & $(13.38 \%)$ & $(10.09 \%)$ & $(3.20 \%)$ & $(2.95 \%)$ & $(7.06 \%)$ & $(4.24 \%)$ & $(16.48 \%)$ & $(9.56 \%)$ \\
F & {$[80 \% \sim 100 \%)$} & 557.25 & 506.81 & 136.38 & 127.38 & 142.50 & 240.75 & 289.50 & 465.25 \\
& & $(20.35 \%)$ & $(18.51 \%)$ & $(4.98 \%)$ & $(4.65 \%)$ & $(5.20 \%)$ & $(8.79 \%)$ & $(10.57 \%)$ & $(16.99 \%)$ \\
G & $100 \%$ & 197.25 & 441.13 & 260.13 & 202.13 & 112.00 & 137.69 & 106.63 & 216.94 \\
& & $(7.20 \%)$ & $(16.11 \%)$ & $(9.50 \%)$ & $(7.38 \%)$ & $(4.09 \%)$ & $(5.03 \%)$ & $(3.89 \%)$ & $(7.92 \%)$ \\
\hline
\end{tabular}

A, area never submerged by water, such as bottomland; B, sedge area rarely submerged by water and near the bottomland; C, D and E, marshland with different moisture; F, area submerged by water most of times over the year, there were many water plants when the area was exposed; G, area submerged by water all the time, such as the middle of the lake and main river.

The composition of the habitat changed with seasons. The statistics showed that most area of milu habitat was never submerged in water wholly (Table III). The proportion of level E $(60 \% \sim 80 \%)$ and $\mathrm{F}(80 \% \sim 100 \%)$ reduced increasingly from spring to winter except summer. Level A $(0 \%)$ was prominent in all periods. The proportion of level D $(40 \% \sim 60 \%)$, E $(60 \% \sim 80 \%)$, F $(80 \%$ $100 \%$ ) increased from dry periods to wet periods while level $\mathrm{A}(0 \%)$ and $\mathrm{C}(20 \% \sim 40 \%)$ reduced, meanwhile, the proportionate change of level B $(20 \% \sim 40 \%)$ and $\mathrm{G}$ (100\%) was inconsistent in 2016 and 2017, indicating that the proportion of each level changed according to water level, especially the area where MSTI was more than $40 \%$. The utilization of each level in different periods is shown in Figure 6. The level A $(0 \%)$ was most utilized by the milu population, and level F (80\% 100\%) and G (100\%) where water level was maintained nearly over the year was also favorite. 


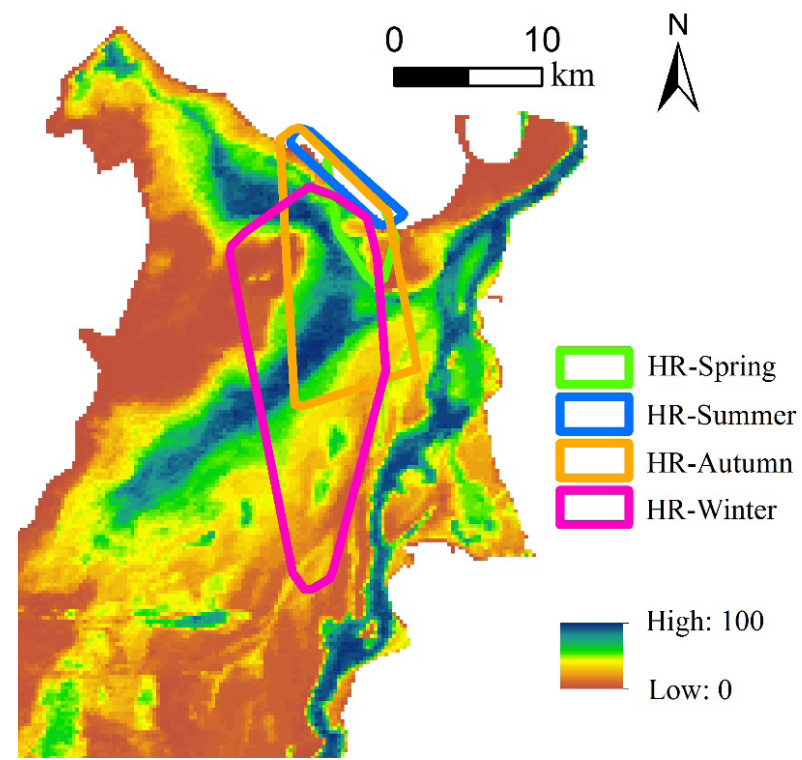

Fig. 5. Seasonal home range and max-submersion time index of Dongting Lake.

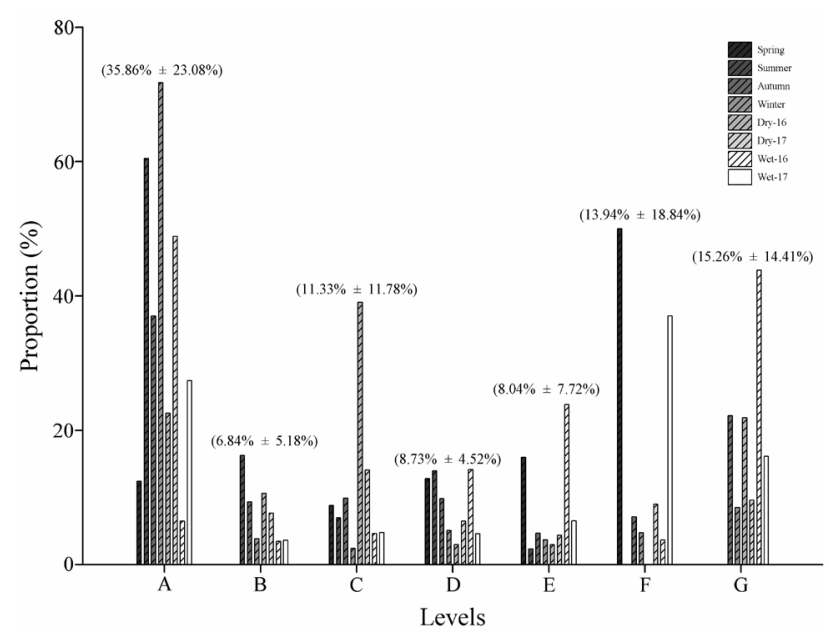

Fig. 6. The proportion of MSTI utilization in different periods.

\section{DISCUSSION}

Water supply in Dongting Lake maximizes from June to September (Wang et al., 1998; Shi et al., 2012), thus the water level varies considerably during the summer or breeding period. Water surface area of Dongting Lake is considered as the significant factor that influences the distribution of milu (Yang et al., 2016). Except for the changing level in the lake human disturbance is probably the main external factor that influences the HR of milu. The milu population suffers greatly from human disturbance and they only live in the circumscribed area. After the wet period is over, the milu population returns to the inner portion of the Dongting Lake wetland to search the favorite food and avoid human disturbance.

Food resources are one of the factors related to HR (Damuth, 1981). The milu usually eat plants with low amounts of fibrous material, however, they sometimes eat dry grass or branches when the preferred food resources are unavailable (Wang and Wang, 2011). There is a great diversity of plants in the Dongting Lake wetland, with carex (Carex brevicuspis), reed (Phragmites australis), and poplar (Populus euramericana) being the main species (Yuan, 2008). Dongting Lake wetland is a suitable habitat for the milu population as it contains abundant food, water and shelter. Other animal species are also abundant in Dongting Lake wetland, including birds and livestock, while there are no predators of milu in this region (Yang et al., 2005). At the same time, the milu population living in Dongting Lake faces low inter-specific competition. The water level may hinder milu foraging, thus, water influences the relationship of HR with food availability indirectly (Yang et al., 2016).

The present study combined the HR with the MSTI of Dongting Lake, and showed that the hierarchy of MSTI was progressive. The overlay analysis showed that the land area almost covered by water had high utilization by milu population. Based on the location points, however, the core area of Dongting Lake was not utilized by milu. The milu population habitat should cover various types of land use and active area (level A) and water sources (level F and level G) must be included. Both the two types of land use should also be connected by vegetation and should not be too far apart.

\section{CONCLUSION}

The aim of the present study was to explore the spatial utilization of the female milu population living in Dongting Lake wetland during different periods. According to the home range size during different periods, spatial utilization of the population is related to water level. When water levels rise, milu changes habitat passively due to water surface extension. During such periods (summer, wet period), HR size was smaller than that of the previous period, and the milu may even live out of the lake where human disturbance is common. The milu migrate back to the inner region of Dongting Lake until the water surface area recedes, and they move to the choice habitats. Available food for milu is widely distributed, however the searching process is impeded when water level increase. The milu habitat covers various types of land use and active area and water sources must be included. The two types of 
land use should also be connected through vegetation and should not be too far apart. The relationship between water surface area with HR can be reflected by maximum flood time index utilization.

\section{ACKNOWLEDGMENTS}

We are indebted to Hunan Eastern Dongting Lake National Nature Reserve Management for their help when we investigated population in the wild. The tracking equipment was provided by Hunan Global Messenger Co. Ltd. Animal Ethics Clearance was obtained from the Animal Ethics Committee, Central South University of Forestry and Technology (with ethics number XLK201525) and the project is under the supervision of the Chinese Forestry and Grassland Administration. This work was supported by National Natural Science Foundation of China (U20A20118), Forestry Science and Technology Project of Hunan Province (XLK201525), Natural Science Foundation of Hunan Province (2019JJ40012) and Key Technology R\&D Program of Hunan Province (2016TP1014; 2017TP2014; 2017TP2006).

\section{Statement of conflict of interest}

The authors have declared no conflict of interests.

\section{REFERENCES}

Burt, W.H., 1943. Territoriality and home range concepts as applied to mammals. J. Mammal., 24: 346-352. https://doi.org/10.2307/1374834

Cao, L., Barter, M. and Lei, C., 2008. New Anatidae population estimates for eastern China: Implications for current flyway estimates. Biol. Conserv., 141: 2301-2309. https://doi.org/10.1016/j. biocon.2008.06.022

Cao, X.Y., Lv, Y. and Liu, Y.C., 2010. Investigation on peripheral community resident's dependence and attitude to Dongting Lake. J. NW For. Univ., 25: 221-224.

Chen, J.X., Xu, L.G., Jiang, J.H., Tan, Z.Q., Yu, Q.W. and Fang, H.X., 2016. The research of runoff responses to climate change and human activities in the Dongting Lake catchment. J. Agro-Environ. Sci., 35: 2146-2153.

Damuth, J., 1981. Home range, home range overlap, and species energy use among herbivorous mammals. Biol. J. Linn. Soc., 153: 185-193. https://doi. org/10.1111/j.1095-8312.1981.tb00758.x

Ding, Y.H., Ding, J.J., Li, P.F. and Zhu, J.Q., 2018. Strategy study of wild Pere David deer (Elaphurus davidianus) population development in China. J.
Jiangsu For. Sci. Technol., 45: 49-51.

Flanagan, S.E., Brown, M.B., Fennessy, J. and Bolger, D.T., 2016. Use of home range behaviour to assess establishment in translocated giraffes. Afr. J. Ecol., 54: 365-374. https://doi.org/10.1111/aje.12299

Guan, L., Lei, J.L., Zuo, A.J., Zhang, H., Lei, G.C. and Wen, L., 2016. Optimizing the timing of water level recession for conservation of wintering geese in Dongting Lake, China. Ecol. Eng., 88: 90-98. https://doi.org/10.1016/j.ecoleng.2015.12.009

He, Z., Yang, D.D., Ma, J.Z., Li, P.F. and Jiang, Z.G., 2007. Winter Habitat Selection by milu in Shishou, Hubei. Sichuan J. Zool., 26: 764-768.

Huang, S.F., Li, J.G. and Xu, M., 2012. Water surface variations monitoring and flood hazard analysis in Dongting Lake area using long-term Terra/MODIS data time series. Nat. Hazards, 62: 93-100. https:// doi.org/10.1007/s11069-011-9921-6

Huang, T., Xu, Z.G., Zhou, L.B. and Zhao, Y.L., 2019. Home range associated with water surface variations for wintering Cygnus columbianus in Dongting Lake. Acta Ecol. Sin., 39: 8657-8666. https://doi.org/10.5846/stxb201804260951

Jiang, Z.G., Li, C.W., Peng, J.J. and Hu, H.J., 2001. Structure, elasticity and diversity of animal behavior. Chinese Biodivers., 9: 265-274.

Kaczensky, P., Ganbaatar, O., Wehrden, H.V. and Walzer, C., 2010. Resource selection by sympatric wild equids in the Mongolian Gobi. J. appl. Ecol., 45: 1762-1769. https://doi.org/10.1111/j.13652664.2008.01565.x

Kernohan, B.J., Gitzen, R.A. and Millspaugh, J.J., 2001. Analysis of Animal Space Use and Movements. In: Radio tracking and animal populations (eds. J.J. Millspaugh and J.M. Marzluff). Academic Press, pp. 125-166. https://doi.org/10.1016/B978012497781-5/50006-2

Lai, X.J., Jiang, J.H. and Huang, Q., 2013. Effects of the normal operation of the Three Gorges Reservoir on wetland inundation in Dongting Lake, China: A modelling study. Hydrolog Sci. J., 58: 1467-1477. https://doi.org/10.1080/02626667.2013.831418

Li, C.W., Jiang, Z.G., Tang, S.H. and Zeng, Y., 2007. Evidence of effects of human disturbance on alert response in Pere David's deer (Elaphurus davidianus). Zoo Biol., 26: 461-470. https://doi. org/10.1002/zoo.20132

Li, F., Huang, J.H., Zeng, G.M., Yuan, X.Z., Li, X.D., Liang, J., Wang, X.Y., Tang, X.J. and Bai, B., 2013. Spatial risk assessment and sources identification of heavy metals in surface sediments from the Dongting Lake, Middle China. J. Geochem. 
Explor., 132: 75-83. https://doi.org/10.1016/j. gexplo.2013.05.007

Li, Y.Z., Bian, H.L., Ren, B., Xie, Y.H., Ding, X.H., Yao, X. and Zhou, Q.Q., 2019. Morphological responses of two plant species from different elevations in the Dongting Lake wetlands, China, to variation in water levels. Nord J. Bot., 31: 7. https://doi. org/10.1111/njb.01987

Liang, C.Q. and Li, B.S., 1991. The habitat vegetation of semi-free range milu (Elaphurus davidianus). Sci. Sli. Sin., 27: 425-434.

Liang, J., Liu, J.Y., Yuan, X.Z., Zeng, G.M., Lai, X., Li, X.D., Wu, H.P., Yuan, Y.J. and Li, F., 2015. Spatial and temporal variation of heavy metal risk and source in sediments of Dongting Lake wetland, mid-south China. J. environ. Sci. Heal A, 50: 100108. https://doi.org/10.1080/10934529.2015.96463 6

Liu, N., 2014. Bellowing mechanism and mating success of reproductive strategies in Père David's deer stag. Sichuan Agriculture University.

Meng, H., Wu, H.J., Zhang, L.Y., Han, C.M. and Gao, Q.H., 2014. Analysis on genetic diversity in mtDNA control region of Elaphurus davidianus (EIK). J. econ. Anim., 18: 15-18.

Plotz, R.D., Grecian, W.J., Kerley, G.I.H. and Linklater, W.L., 2016. Standardising home range studies towards improved management of the critically endangered black rhinoceros. PLoS One, 11: e0150571. https://doi.org/10.1371/journal. pone. 0150571

Rautio, A., Valtonen, A. and Kunnasranta, M., 2013. The effects of sex and season on home range in European hedgehogs at the northern edge of the species range. Annls. Zool. Fenn., 50: 107-123. https://doi.org/10.5735/086.050.0110

Reinecke, H., Leinen, L., Thissen, I., Meissner, M., Herzog, S., Schutz, S. and Kiffner, C., 2014. Home range size estimates of red deer in Germany: Environmental, individual and methodological correlates. Eur. J. Wildl. Res., 60: 237-247. https:// doi.org/10.1007/s10344-013-0772-1

Sarkar, M.S., Ramesh, K., Johnson, J.A., Sen, S., Nigam, P., Gupta, S.K., Murthy, R.S. and Saha, G.K., 2016. Movement and home range characteristics of reintroduced tiger (Panthera tigris) population in Panna Tiger Reserve, central India. Eur. J. Wildl. Res., 62: 1-11. https://doi.org/10.1007/s10344016-1026-9

Shi, X., Xiao, W.H., Wang, Y. and Wang, X., 2012. Characteristics and factors of water level variations in the Dongting Lake during the recent 50 years.
SN Water Diversion Water Sci. Technol., 10: 18-22. Song, Y.C., Yang, D.D., Zou, S.J., Li, P.F., Zhang, H., Wen, H.J. and Jiang, Z.G., 2015. Sex-biased dispersal in naturally re-wild milu in the Dongting Lake Region China. Acta Ecol. Sin., 35: 44164424. https://doi.org/10.5846/stxb201408251680

Tan, Q.L., 2002. Study on remote sensing change detection andits application to Poyang International Importance Wetland. Chinese Academy of Science.

Tian, W.G., Peng, J.D., Shen, J. and Li, S., 2012. Sequence analysis on the area of Dongting Lake before and after building three gorges dam based on MODIS image sequences. J. Anhui agric. Sci., 40: 9141-9145.

Wang, S.M., Dou, H.S., Chen, K.Z., Wang, X.C. and Jiang, J.H., 1998. The history of Chinese Lakes, $1^{\text {st }}$ ed. Science Press, Beijing.

Wang, S.Y., Zhao, Y.L., Xu, Z.G., Li, L., Wu, L., Duan, C.C. and Peng, J., 2017. Behavioural rhythms during the adaptive phase of introduced milu/ Pere David's deer, Elaphurus davidianus, in the Dongting Lake Wetland, China. Pakistan J. Zool., 49: 1657-1664. https://doi.org/10.17582/journal. pjz/2017.49.5.1657.1664

Wang, X., Cao, L., Fox, A.D., Fuller, R., Griffin, L., Mitchell, C., Zhao, Y.L., Moon, O.K., Cabot, D., Xu, Z.G., Batbayar, N., Kölzsch, A., van der Jeugd, H.P., Madsen, J., Chen, L.D. and Nathan, R., 2019. Stochastic simulations reveal few green wave surfing populations among spring migrating herbivorous waterfowl. Nat. Commun., 10: 12. https://doi.org/10.1038/s41467-019-09971-8

Wang, Y. and Wang, W., 2011. Diet of Père David's deer (Elaphurus davidianus) at Milu Park in Beijing, China. Chinese J. Wildl., 32: 65-68.

Willems, E.P. and Hill, R.A., 2009. Predator-specific landscapes of fear and resource distribution: effects on spatial range use. Ecology, 90: 546-555. https:// doi.org/10.1890/08-0765.1

Yang, D.D., Jiang, Z.G., Cao, T.R., Wen, S.Z., Zhao, K.J., Gui, X.J. and Xu, Y.X., 2002. Feasibility of reintroducing Père David's deer (Elaphurus davidianus) to the Dongting Lake region, Hunan Province. Chinese Biodivers., 10: 369-375.

Yang, D.D., Song, Y.C., Ma, J.Z., Li, P.F., Zhang, H., Price, M.R.S., Li, C.L. and Jiang, Z.G., 2016. Stepping-stones and dispersal flow: establishment of a meta-population of milu (Elaphurus davidianus) through natural re-wilding. Scient. Rep., 6: 27297. https://doi.org/10.1038/srep27297

Yang, D.D., Ma, J.Z., He, Z., Li, P.F., Wen, H.J. and Jiang, Z.G., 2007. Population dynamics of the Père 
David's deer Elaphurus davidianus in Shishou Milu National Nature Reserve, Hubei Province, China. Acta Zool. Sin., 53: 947-952.

Yang, D.D., Jiang, Z.G., Ma, J.Z., Hu, H.J. and Li, P.F., 2005. Causes of endangerment or extinction of some mammals and its relevance to the reintroduction of Père David's deer in the Dongting Lake drainage area. Biodivers. Sci., 13: 451-461. https://doi. org/10.1360/biodiv.050031

Yuan, Z.K., 2008. Resources and environment of wetland in Dongting Lake, $1^{\text {st }}$ ed. Hunan Normal University Press, Changsha.
Zhang, C., Yuan, Y.J., Zeng, G.M., Liang, J., Guo, S.L., Huang, L., Hua, S.S., Wu, H.P., Zhu, Y., An, H.X. and Zhang, L.H., 2016. Influence of hydrological regime and climatic factor on waterbird abundance in Dongting Lake Wetland, China: Implications for biological conservation. Ecol. Eng., 90: 473-481. https://doi.org/10.1016/j.ecoleng.2016.01.076

Zhang, S.M., Liang, B.K., Zhang, L.Y. and Hu, D.F., 2011. Challenges of Farmed Père David's deer population development and its protection strategy. For. Inventor. Plann., 36: 128-132. https://doi. org/10.1016/j.energy.2011.01.035 